\title{
Soluble Plant Cell Signals Induce the Expression of the Type III Secretion System of Pseudomonas syringae and Upregulate the Production of Pilus Protein HrpA
}

\author{
Minna Haapalainen, ${ }^{1}$ Kristin van Gestel, ${ }^{1}$ Minna Pirhonen, ${ }^{2}$ and Suvi Taira ${ }^{1}$ \\ ${ }^{1}$ Division of General Microbiology, Department of Biological and Environmental Sciences, P.O.B. 56, and ${ }^{2}$ Department \\ of Applied Biology, 00014 University of Helsinki, Finland
}

Submitted 27 June 2008. Accepted 26 November 2008.

\begin{abstract}
Type III protein secretion is essential for the pathogenicity of Pseudomonas syringae on its host plants. Expression of HrpA, a major component of the type III secretion system (T3SS)-associated pilus, was studied both in plant leaves and in vitro using reporter genes. We found that induction of the $h r p A$ promoter was stronger in plants than in vitro, and that the induction was enhanced by both host and nonhost plants of $P$. syringae pv. tomato. In vitro, the expression was enhanced by cell-free exudates from plant cell suspension cultures, added into the minimal medium. Further analysis of the plant-cell-derived, $h r p A$-inducing factors showed that they were small and water-soluble compounds, which could signal $P$. syringae the proximity of living plant cells. We also studied the production and secretion of native HrpA protein in vitro, and detected a plantsignal-dependent increase in HrpA secretion. In contrast to HrpA, the intracellular accumulation or secretion of the other T3SS-dependent proteins were not significantly increased, despite the presence of plant cell-derived, promoter-inducing factors. Thus, the accumulation of HrpA pilin seems to be subjected to a distinct post-transcriptional regulation.
\end{abstract}

Pseudomonas syringae is a widespread pathogen infecting the aerial parts of plants, causing spots on leaves and fruits and cankers on stems. To infect plants, $P$. syringae relies on a special protein secretion pathway, the type III secretion system (T3SS), to deliver virulence or effector proteins into the plant cells. Many gram-negative bacterial pathogens of plants and animals, and also plant symbionts, use T3SS injectisome to deliver proteins into the eukaryotic cells (Hueck 1998; Marie et al. 2001). The injected effector proteins of plant pathogens function to suppress the host defense responses in many ways (such as plant pathogens) (Grant et al. 2006). The T3SS apparatus includes a bacterial cell-wall-puncturing protein complex, an extracellular needle-like part, and a translocation complex assembled into the host cell membrane (Cornelis 2006). Thus, the secretion machinery transports the proteins over three membranes, the bacterial inner and outer membrane and the host cell membrane. For the plant pathogens, there is still another challenging barrier: the thick wall surrounding the plant cells. To reach the host cells, $P$. syringae delivers the T3SS-dependent proteins by means of long pili (Brown et al. 2001; Li et al. 2002), which are built up of HrpA protein sub-

Corresponding author: Minna Haapalainen;

E-mail: minna.haapalainen@helsinki.fi units (Roine et al. 1997). The HrpA pilin shares no sequence homology with the needle proteins of animal pathogens, such as YscF of Yersinia spp., although the pilus and the needle are assumed to be functionally analogous.

In $P$. syringae, the T3SS is induced when the bacteria get into the leaf mesophyll through stomata (Boureau et al. 2002), but it can also be induced in vitro in a suitable minimal medium mimicking the host environment (Huynh et al. 1989) whereas, in a rich culture medium, the system is suppressed. Transcription of the genes encoding the $P$. syringae T3SS components and the effector proteins is activated by the binding of HrpL, the $\alpha^{\mathrm{L}}$ factor, at the so-called hrp box sequence upstream of these genes (Xiao and Hutcheson 1994). Expression of $\mathrm{HrpL}$ is activated by $\mathrm{HrpR}$ and HrpS, two homologous DNA-binding proteins that function as a heterodimer (Hutcheson et al. 2001). When the expression of the T3SS of $P$. syringae is induced in vitro, the T3SS-dependent proteins are still secreted and, in the absence of host cells, released into the medium. Thus, the protein secretion in P. syringae is not tightly coupled with the translocation event. In the animal pathogens Yersinia and Shigella spp., translocation of virulence factors is triggered by host cell contact (Deane et al. 2006; Rosqvist et al. 1994; Toruellas et al. 2005); however, whether this also holds true for the $P$. syringae-plant interaction is not known. The expression and secretion of different T3SS-dependent proteins can be controlled by different regulatory mechanisms and, for individual proteins, the secretion can be uncoupled from the gene expression. In $P$. syringae pv. syringae, secretion of the effector proteins HopA1 (previously HopPsyA) and AvrPto was found to be upregulated at low temperatures (18 to $22^{\circ} \mathrm{C}$ ) and $\mathrm{pH} 6.0$ in vitro. In contrast, secretion of HrpZ, which is a T3SS-assisting protein, was insensitive to temperature in the range from 18 to $30^{\circ} \mathrm{C}$ (Van Dijk et al. 1999). However, the accumulation of any of these three proteins inside the bacterial cells was not sensitive to $\mathrm{pH}$ or temperature, because the gene expression was active in a fructose-containing minimal medium within $\mathrm{pH}$ range 5.0 to 7.0 and temperatures of 18 to $30^{\circ} \mathrm{C}$.

In this work, we studied the expression of HrpA, the T3SS pilin of $P$. syringae pv. tomato, by several methods: by fusion of two marker genes to $h r p A$ promoter to determine when and where $h r p A$ gene is induced, and by detecting the amount of native HrpA protein produced and secreted under different culture conditions. The fusion construct with green fluorescing protein was used to observe $h r p A$ expression in situ, in infected plant leaves, and in cell suspension cultures, whereas fusion with luciferase enabled us to measure quantitatively the level of hrpA promoter activity. We used the activity of the hrpA pro- 
moter as a measure of transcriptional activity of the whole T3SS of $P$. syringae pv. tomato. To test whether the other genes encoding T3SS-dependent proteins actually are induced in the same in vitro conditions as $h r p A$, we also constructed luciferase gene fusions with the promoters of hrpK and avrPto genes. hrpK encodes a putative translocator (Petnicki-Ocwieja et al. 2005) and, thus, represents a component of the T3SS machinery, whereas avrPto, which encodes an effector protein that suppresses plant defense (Hauck et al. 2003), represents a T3SS substrate protein. We found that the $h r p K$ promoter and avrPto promoter were also induced in the minimal medium and in planta, and that the in vitro induction of these promoters was enhanced by the tomato cell exudates. However, the avrPto promoter showed slightly slower induction kinetics than hrpA and $h r p K$ promoters. For HrpA, the protein accumulation and secretion were also significantly increased in the presence of plant-derived compounds in vitro, whereas the accumulation of HrpK or AvrPto protein was not increased, despite the promoter activation observed in the luciferase assays. This suggests that the accumulation of HrpA pilin is controlled post-transcriptionally and differently from the other T3SS components.

\section{RESULTS}

\section{Both hrpA-green fluorescent protein and} hrpA-luciferase expression were induced in the presence of viable plant cells.

P. syringae pv. tomato DC3000 was transformed with a plasmid construct encoding click beetle luciferase (LucGR) under hrpA promoter (pHrpALUC). The transformants carrying this construct and the previously made hrpA-green fluorescent protein (GFP) construct (Boureau et al. 2002) expressed the marker genes in vitro under $h r p$-inducing conditions, in minimal medium at $18^{\circ} \mathrm{C}$, indicating that the constructs were fully functional. When hrpA-GFP transformants were infiltrated into the leaves of Arabidopsis thaliana, green fluorescing bacteria could be detected in the leaves $7 \mathrm{~h}$ later. After overnight incubation, the infiltrated leaves were full of fluorescing bacteria (Fig. 1A). Similarly, when $P$. syringae hrpA-GFP transformants were incubated together with viable tomato cells in suspension culture, the fusion protein expression was induced, and the maximal expression level was reached in $4 \mathrm{~h}$ after inoculation (Fig. 1B). Instead, dead tomato cells or isolated tomato cell wall material, prepared similarly to Aldon and associates (2000), did not induce HrpA-GFP expression. When the HrpA-GFP expression was induced in the suspension culture, fluorescing bacteria were observed both in contact with the tomato cells and apart from them. The bacteria did not seem to attach firmly to the tomato cells, and the amount of bacterial cells in close contact with tomato cells did not increase with time.

Expression of stable GFP cannot be easily quantified, whereas the expression level of the luciferase enzyme can be determined quantitatively, and the operative range of the assay is broad. When testing the pHrpALUC transformants on tomato and tobacco leaves, the luciferase expression reached a high level $4 \mathrm{~h}$ after infiltration (Fig. 2). The hrpA promoter induction, measured as luminescence per number of viable bacterial cells, was 5 to 15 times stronger in the plants than it was in the hrpinducing medium $4 \mathrm{~h}$ after inoculation (Fig. 2; Table 1). Luciferase activity in a control strain transformed with the luciferase vector $\mathrm{pPP}$ without any promoter was almost nondetectable in all conditions tested (Fig. 2; data not shown).

\section{Luciferase expression under $h r p A$ promoter was induced by cell-free exudates of cultured tomato cells.}

Direct contact with tomato cells seemed not to be required for $h r p A$ induction in $P$. syringae pv. tomato; therefore, we studied the effect of cell-free tomato exudates on pHrpALUC transformants. We found that inducing factors were released by tomato cells into phosphate buffer, which could then be used as a conditioned buffer (CB) for inducing $h r p A$ promoter without the presence of tomato cells. Thus, the inducing factors were not cell-bound but soluble and diffusive. A 10-fold enhancement in hrpA expression was observed in CB compared with the plain phosphate buffer (Fig. 3A). Viability of the tomato cell culture was found crucial for the production of hrpA-inducing factors: dead cells did not release inducing factors (data not shown). To study the importance of active protein synthesis in producing the inducing factors, tomato cells were incubated with $100 \mu \mathrm{M}$ cycloheximide, an inhibitor of eukaryotic translation, during the preparation of the conditioned buffer. Treating the cells with this inhibitor during the $4 \mathrm{~h}$ of incubation clearly reduced $h r p A$-inducing activity of CB (Fig.
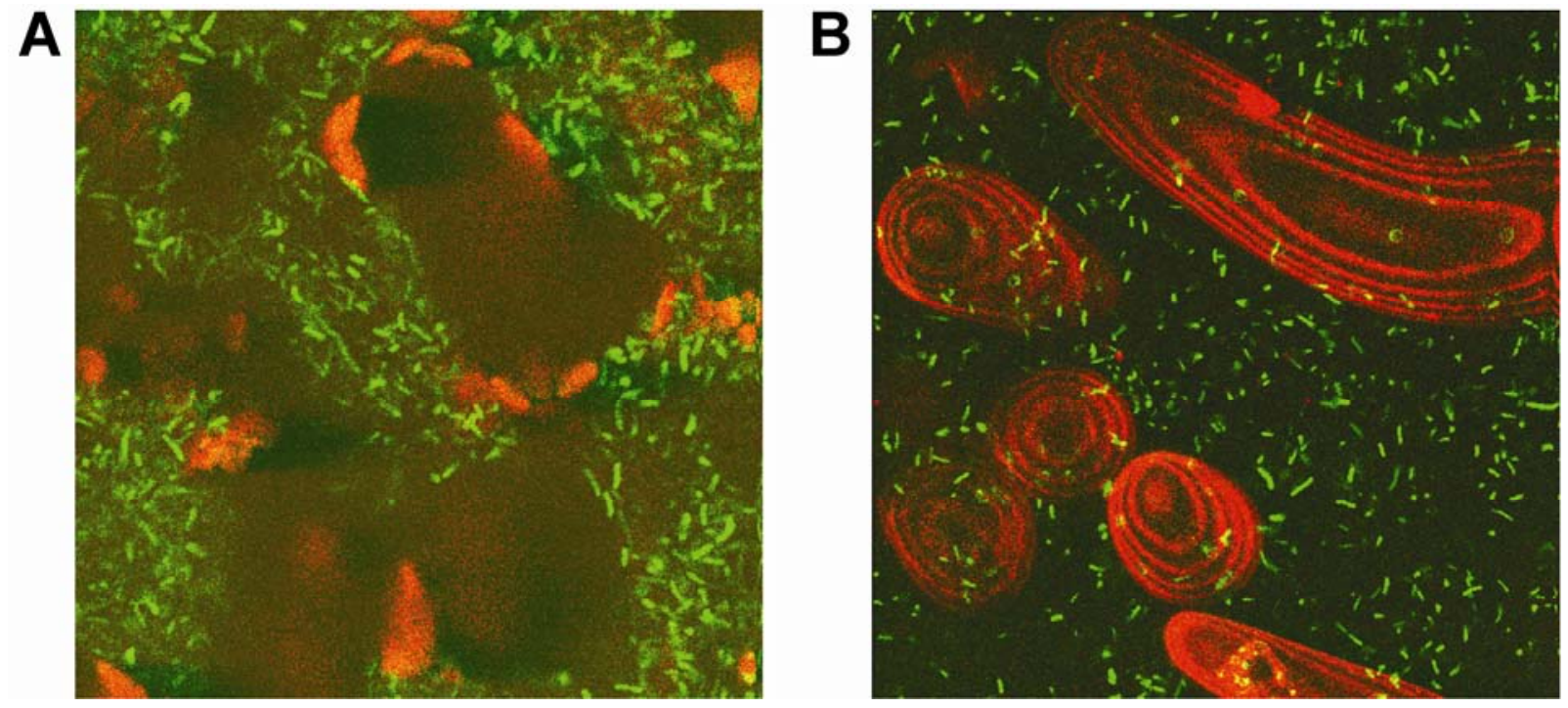

Fig. 1. Expression of hrpA-green fluorescent protein $(G F P)$ in Pseudomonas syringae in the presence of plant cells, imaged by fluorescence microscopy. A, Bacteria expressing green fluorescence between parenchymal cells in a leaf of Arabidopsis thaliana, $7 \mathrm{~h}$ after infiltration at an optical density at $600 \mathrm{~nm}=0.1$. B, Bacteria expressing green fluorescence in tomato cell suspension culture, $4 \mathrm{~h}$ after inoculation. To create a three-dimensional picture of the tomato cells, several confocal microscopy images scanned at different depths are combined in this image. Plant cell structures emit red light under the fluorescence excitation. 
3B). This suggests that the production of the inducing factors may require de novo protein synthesis.

The expression of $h r p A-L U C$ was not dependent on the growth of the bacteria in the induction medium but was dependent on the initial cell density.

Expression of hrpA-LUC increased sharply in CB already during the second hour after inoculation, and the maximal expression level was reached in $4 \mathrm{~h}$ of incubation (Fig. 3A and
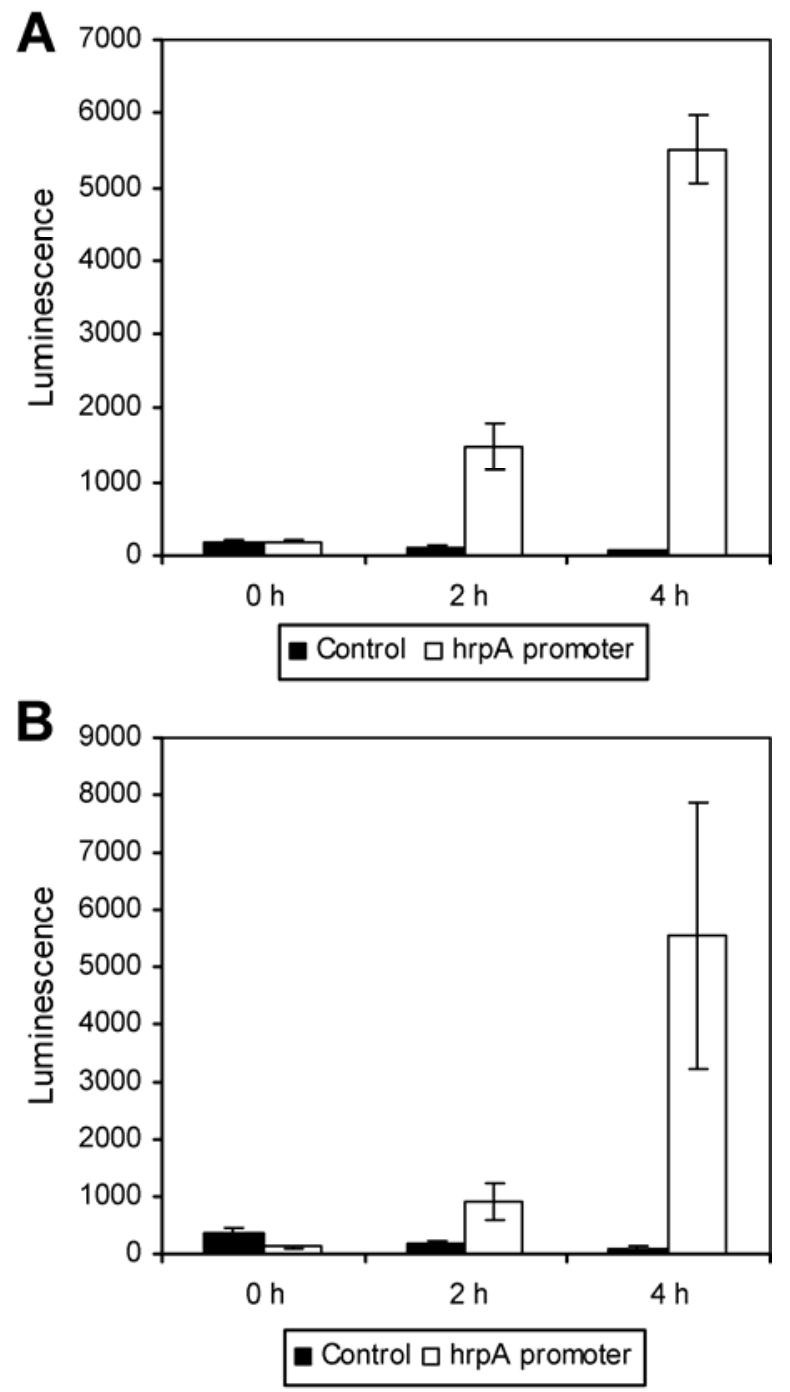

Fig. 2. Expression of hrpA-luciferase (LUC) in Pseudomonas syringae infiltrated in the leaves of $\mathbf{A}$, tomato and $\mathbf{B}$, tobacco. The figures shown are luminescence counts per $10^{6} \mathrm{CFU}$, averages of four independent infiltrations, with error bars indicating standard deviation. Control strain DC3000 carrying the luciferase plasmid $\mathrm{pPP}$ without any promoter was infiltrated into plant leaves similarly to the $h r p A-L U C$ strain.
B). Within this time, the cell density of the induction cultures did not change. In order to study later timepoints and the effect of bacterial multiplication on hrpA-LUC induction, we studied the $h r p$-inducing minimal medium (HIM), conditioned with tomato cell exudates (CHM). Also in HIM and CHM, the bacteria did not multiply significantly during the first $4 \mathrm{~h}$ and, after $20 \mathrm{~h}$, the cell density of the cultures had only increased by $50 \%$. However, the luciferase expression increased to very high levels during overnight incubation in CHM in spite of the low growth rate (Table 1). In contrast to growth, there seemed

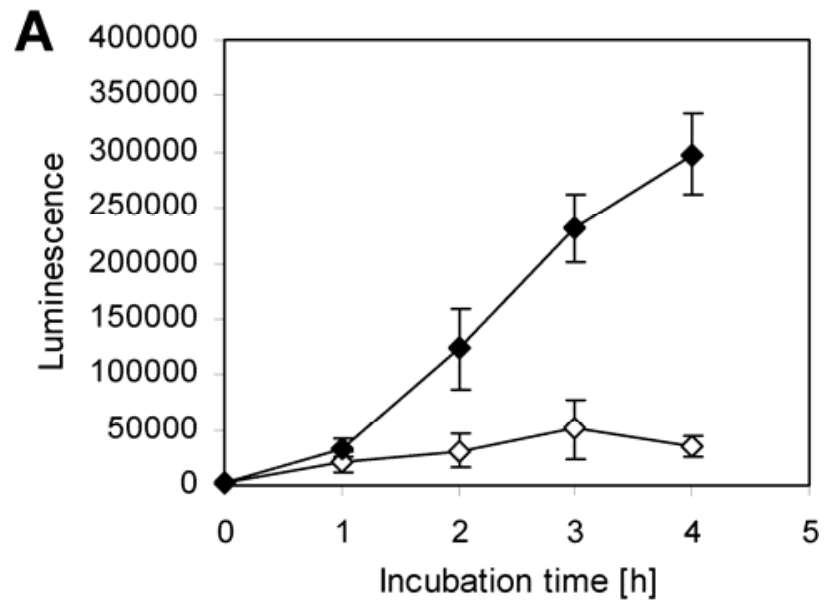

B

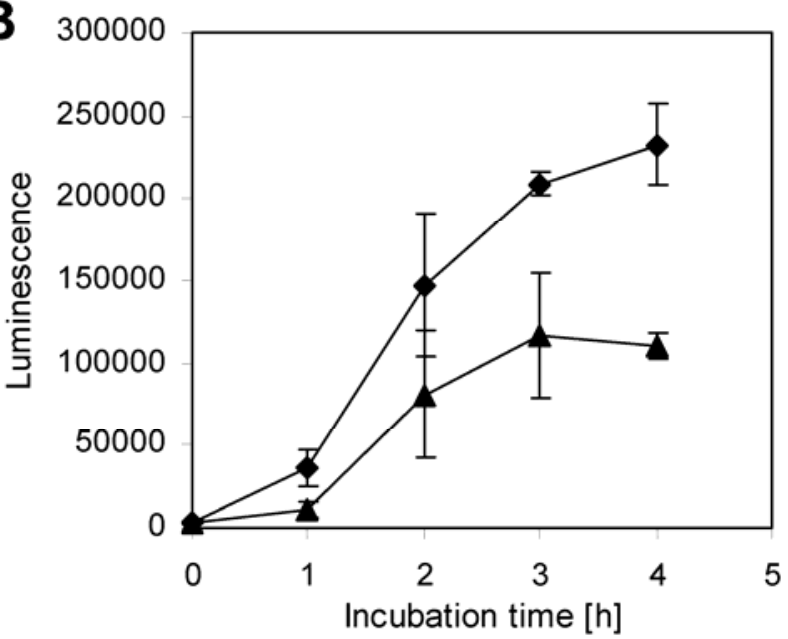

Fig. 3. Induction of hrpA-luciferase ( $L U C$ ) by tomato cell exudates in vitro. A, Luciferase activity expressed by DC3000 pHrpALUC transformants incubated in $10 \mathrm{mM} \mathrm{K}$-phosphate buffer/1.7 $\mathrm{mM} \mathrm{MgCl}_{2}$ (open diamonds) and in the same buffer with tomato cell exudates (solid diamonds). The graph is an average of 15 independent experiments, error bars indicating standard deviations. B, Luciferase activity expressed in the tomato cellconditioned buffer (diamonds) and in conditioned buffer prepared in the presence of $100 \mu \mathrm{M}$ cycloheximide (triangles), which inhibits eukaryote protein synthesis. Graph B is an average of three independent experiments. $\mathbf{A}$ and $\mathbf{B}$, Luminescence counts are shown per $3 \times 10^{7}$ bacterial cells.

Table 1. Tomato cell exudates mixed in the $h r p$-inducing medium enhanced the expression of luciferase under $h r p A$ and $h r p K$ promoters

\begin{tabular}{|c|c|c|c|c|}
\hline \multirow[b]{2}{*}{ Luciferase expression construct } & \multirow[b]{2}{*}{ Induction medium ${ }^{b}$} & \multicolumn{3}{|c|}{ Luminescence, counts per $10^{6}$ cells $^{a}$} \\
\hline & & $\mathbf{O} \mathbf{h}$ & $4 \mathrm{~h}$ & $20 \mathrm{~h}$ \\
\hline \multirow[t]{2}{*}{ hrpA-LUC } & HIM & $168.6( \pm 6.6)$ & $384.8( \pm 132,9)$ & $2,324.0( \pm 141.4)$ \\
\hline & $\mathrm{CHM}$ & $162.1( \pm 3.7)$ & $1,202.5( \pm 139.3)$ & $14,686.1( \pm 6409.6)$ \\
\hline \multirow[t]{2}{*}{$h r p K-L U C$} & HIM & $31.7( \pm 5.7)$ & $210.7( \pm 101.0)$ & $1,411.3( \pm 382.7)$ \\
\hline & $\mathrm{CHM}$ & $36.0( \pm 4.4)$ & $397.8( \pm 23.6)$ & $17,308.4( \pm 8835.9)$ \\
\hline
\end{tabular}

${ }^{a}$ Luminescence counts were proportioned to the bacterial cell density of each Pseudomonas syringae culture at the given timepoints. Figures presented are averages of four assays, and standard deviations are given in parentheses.

${ }^{\mathrm{b}} \mathrm{HIM}$ is the hrp-inducing minimal medium and CHM is HIM supplemented with tomato cell exudates. 
to be a positive correlation between the initial cell density and the $h r p A$ induction level. To obtain high $h r p$ expression levels in the induction cultures, the preculture in King's B medium had to be in an active growth phase with an optical density at $600 \mathrm{~nm}\left(\mathrm{OD}_{600}\right)$ in the range of 0.1 to 0.5 . If the bacterial culture was diluted under $\mathrm{OD}_{600}=0.1$ when changing the culture medium from King's B to HIM or CHM, the expression level per cell was decreased with the dilution (data not shown).

\section{Partial characterization of the $h r p$-inducing factors revealed that they are low molecular weight compounds.}

To characterize the $h r p$-inducing factors released by tomato cells, we fractionated the components of $\mathrm{CB}$ according to the molecular size and hydrophobic characteristics, and tested heat stability of the inducing activity. Fractionation using centrifugal filter devices revealed that the principal inducing factors had a small molecular size, less than $5 \mathrm{kDa}$ (Fig. 4). Results of three independent induction experiments with $\mathrm{CB}$ heated at $100^{\circ} \mathrm{C}$ showed that heating decreased the inducing activity of CB by $34 \%$ on average. Treatment with proteinase $\mathrm{K}$ had no effect on the inducing activity of $\mathrm{CB}$. On solidphase chromatographic separation, the inducing factors did not adhere to the chromatography resins with hydrocarbon ligands, because the flow-through fractions from these columns were still active in $h r p A$ induction. In contrast, the flow-through fractions from the HR-P resin, which preferentially binds phenolic and aromatic compounds, and the polar diol silica resin were inactive, indicating that the inducing factors were bound to these resins. Attempts to elute the inducing factors out of these two adsorbent resins so that they would retain their activity on $P$. syringae were unsuccessful, which prevented further analysis. Thus, we conclude that the inducing factors were nonproteinaceous, moderately hydrophilic, low molecular weight compounds.

\section{Phenolic compounds added to the $h r p$-inducing medium slightly enhanced the $h r p A$ promoter induction.}

Plant-derived phenolic compounds are known to activate the virulence genes of many plant-pathogenic bacteria such as Agrobacterium spp. In order to test whether similar compounds were responsible for the $P$. syringae hrpA induction in $\mathrm{CB}$, we

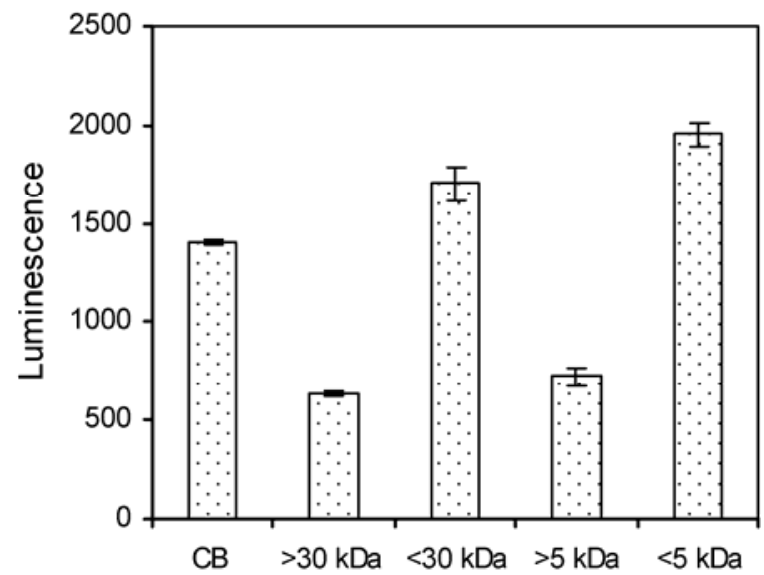

Fig. 4. The hrp-inducing factors released by tomato cells were small molecules. The components of tomato cell-conditioned buffer were size fractionated by filtration, and the fractions were tested for hrpA-luciferase $(L U C)$ induction. Luciferase expression was measured $4 \mathrm{~h}$ after inoculation of the media. The averages of luminescence counts per $10^{6}$ cells for three separate induction cultures are shown, with error bars indicating standard deviation. $\mathrm{CB}$, conditioned buffer prepared by incubating tomato cells in $10 \mathrm{mM} \mathrm{K}$-phosphate buffer/1.7 mM $\mathrm{MgCl}_{2}$; $\mathrm{CB}>30$, over $30 \mathrm{kDa}$ retentate fraction; $\mathrm{CB}<30=$ under $30 \mathrm{kDa}$ filtrate; $\mathrm{CB}>5$, over $5 \mathrm{kDa}$ retentate fraction; $\mathrm{CB}<5=$ under $5 \mathrm{kDa}$ filtrate. added phenolic glucosides arbutin, salicin, helicin, and phenyl$\beta$-D-glucopyranoside to HIM at $100 \mu \mathrm{M}$ concentration. We found that these phenolic glucosides did slightly enhance the luciferase expression (Fig. 5), although the effect was small compared with the inducing activity of the tomato cell exudates. We also tested citric acid and salicylic acid at $1 \mathrm{mM}$ concentration in HIM, and found that these organic acids did not increase luciferase expression. To see whether the $h r p$-inducing effect of CB was due to addition of a plant-cell-derived carbon source, we tested the effect of additional sugars on hrpA promoter induction. Sucrose, glucose, fructose, and lactose added to the nonconditioned $\mathrm{K}$-phosphate/ $\mathrm{MgCl}_{2}$ buffer at $10 \mathrm{mM}$ concentration did not induce $h r p A$ promoter, and glucose was found to repress the expression to a level even lower than in the buffer only (data not shown).

\section{Extracellular accumulation of HrpA protein was enhanced} by tomato cell exudates.

Because protein expression can be controlled at various post-transcriptional steps, we studied the level of native HrpA protein in different culture conditions. The proteins secreted into the culture medium were analyzed after overnight incubation of P. syringae pv. tomato DC3000 in HIM and CHM. A type-three secretion-negative $h r c C$ mutant strain was used as a control, because the panel of T3SS-dependent proteins can be concluded by comparing the extracellular fractions of the wildtype and $h r c C$ strains. The amount of HrpA in the culture supernatant was elevated several-fold in the culture medium containing tomato cell exudates, whereas production of the other T3SS-dependent proteins was only slightly or not at all affected by the plant cell exudates (Fig. 6). Notably, the amount of the major harpin HrpZ was not affected by the tomato cell exudates even though $h r p Z$ lies in the same operon as $h r p A$. The identity of HrpA and HrpZ protein bands was confirmed by immunoblotting. HrpA did not accumulate to high levels inside the bacterial cells, not even in the secretion deficient $h r c C$ strain, suggesting some kind of feedback regulation between secretion and production of HrpA. Slight laddering of HrpA and HrpZ seen in the immunoblot in cellular fractions implies degradation of the proteins trapped inside the cells. The phenolic glucosides tested above for the promoter induction did not have any observable effect on the HrpA protein accumulation (data not shown).

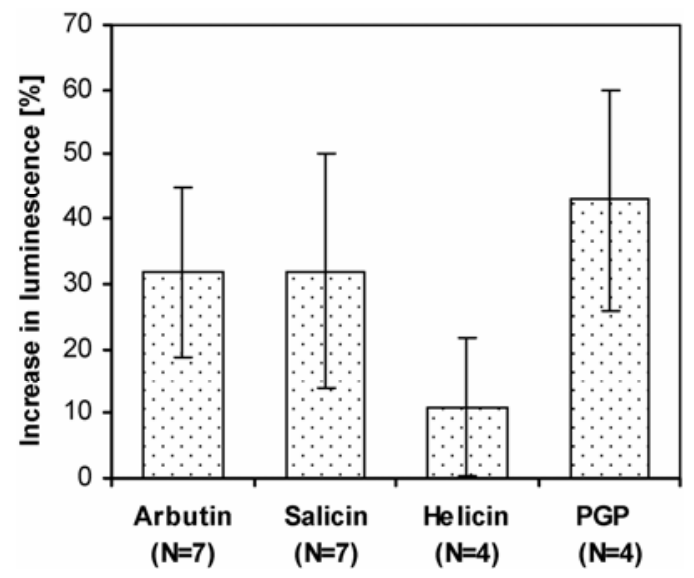

Fig. 5. Luciferase expression under $h r p A$ promoter in the $h r p$-inducing minimal medium supplemented with phenolic glucosides at $100 \mu \mathrm{M}$ concentration. Expression level in the hrp-inducing medium (HIM) was used as the ground level to which the expression in the test cultures was compared in each experiment; $\mathrm{N}$ indicates the number of independent experiments performed, error bars showing standard deviation. PGP is phenyl- $\beta$ D-glucopyranoside. 
Promoter of $h r p K$ was induced similarly to $h r p A$ in planta and in vitro by tomato cell exudates.

HrpA was the only T3SS protein whose accumulation was significantly enhanced by the tomato cell exudates in DC3000; therefore, we studied whether the induction of the other T3SSassociated genes was enhanced by the exudates. We prepared luciferase fusion constructs with the promoters of $h r p K$ and avrPto, a putative translocator and a well-known effector protein. At first, we determined the luciferase expression ratio in hrp-inducing medium compared with King's B. The average induction rates of three independent 4-h induction experiments were 4.2 with $h r p K$ promoter and 2.0 with avrPto promoter. Thus, the induction of $h r p K$ promoter was almost as strong as $h r p A$ induction (fivefold on average), whereas the avrPto promoter did not respond to the minimal medium so well. Both promoters were induced in planta: $h r p K$ promoter $4 \mathrm{~h}$ after infiltration, similarly to hrpA-LUC, and avrPto promoter $6 \mathrm{~h}$ after infiltration (data not shown). The $h r p K$ promoter was, like $h r p A$, also highly induced by the tomato cell exudates during overnight incubation in CHM (Table 1). However, the amount of the $81-\mathrm{kDa} \mathrm{HrpK}$ protein was not massively increased (Fig. 6). Thus, the enhancement of HrpA protein production by plant cell exudates is not directly related to the general hrp gene induction.

\section{DISCUSSION}

Expression of the T3SS in P. syringae is induced by environmental cues which signal the bacteria that they have found a potential host organism. The optimal in vitro hrp-inducing conditions resemble the environment in the plant leaf apoplast: $\mathrm{pH}$ between 5 and 6 , low salt concentrations, and plenty of fructose. Temperatures under $20^{\circ} \mathrm{C}$, like the natural night-time temperatures, are favored. We studied whether there were plant-specific signal molecules which induce hrp expression in addition to those physical environmental cues. It was previously shown that the expression of hrp operons of P. syringae pv. phaseolicola is induced several-fold more in bean leaves than in vitro in M9 or fructose-containing minimal media (Rahme et al. 1992; Thwaites et al. 2004). These results suggest that either the minimal media used for induction are far from optimal or that there are some factors present in the plant leaves which specifically induce the expression of $P$. syringae T3SS. Our results on $P$. syringae pv. tomato confirm that such specific plant signals, sensed by the bacteria to activate T3SS, do exist. Expression of a marker gene under $h r p A$ promoter was higher in plant leaves and in plant cell culture than in a minimal medium without plant-derived material. The hrpinducing compounds could be separated from cultured tomato cells by filtration, stored frozen, and then mixed into the minimal medium to get elevated hrp expression levels in vitro.

Fluorescence microscopy on plant leaves and plant cell cultures inoculated with $P$. syringae pv. tomato DC3000 hrpAGFP transformant showed that hrp expression was also induced in bacteria that were not in contact with the plant cells. This is different from Ralstonia solanacearum, in which the induction of T3SS requires a contact with the host cells and can be induced in vitro by a nondiffusible plant cell wall component (Aldon et al. 2000). We isolated cell wall material from tomato cells using the same method and found that it was not inducing the hrpA expression of $P$. syringae pv. tomato. Thwaites and associates (2004) collected P. syringae pv. phaseolicola together with plant cell debris from pieces of infected bean leaves and found that the bacteria attached to the solid debris expressed hrp genes at a two times higher level than unattached bacteria. However, because the filter residue was not washed, the solid plant material and the bacterial cells were still exposed to all the molecules present in the leaf tissue. Thus, it is not clear which kind of components of the leaf tissue caused the observed enhancement of hrp expression in those experiments. However, it is possible that the combination of soluble plant compounds and contact with the plant cell wall material would give the maximal induction of the hrp genes. If this is the case, then the T3SS of $P$. syringae could be induced by a three-step mechanism: at first by environmental cues, then by soluble plant signals, and further enhanced by plant cell contact. Our results on the kinetics of $h r p A$ promoter induction, which reaches the maximal expression level in $4 \mathrm{~h}$ after inoculation of the plant leaves or the plant-cell-conditioned medium, agrees well with the results of Thwaites and others (2004) on P. syringae pv. phaseolicola in bean leaves.

The soluble $h r p$-inducing factors released by cultured tomato cells proved to be less than $5 \mathrm{kDa}$ in size, moderately heat resistant, and insensitive to proteinase $\mathrm{K}$ treatment. The inducers were only released by living and healthy cells, indicating that their production required active metabolism. The inducers seem to be moderately hydrophilic organic compounds, possibly phenolics or other aromatic compounds. Thus, the inducer recognized by $P$. syringae might resemble the flavonoids recognized by Agrobacterium and Rhizobium spp. to find their host plants. However, unlike those signals, the compounds recognized by $P$. syringae are not host-specific. The hrpA pro-
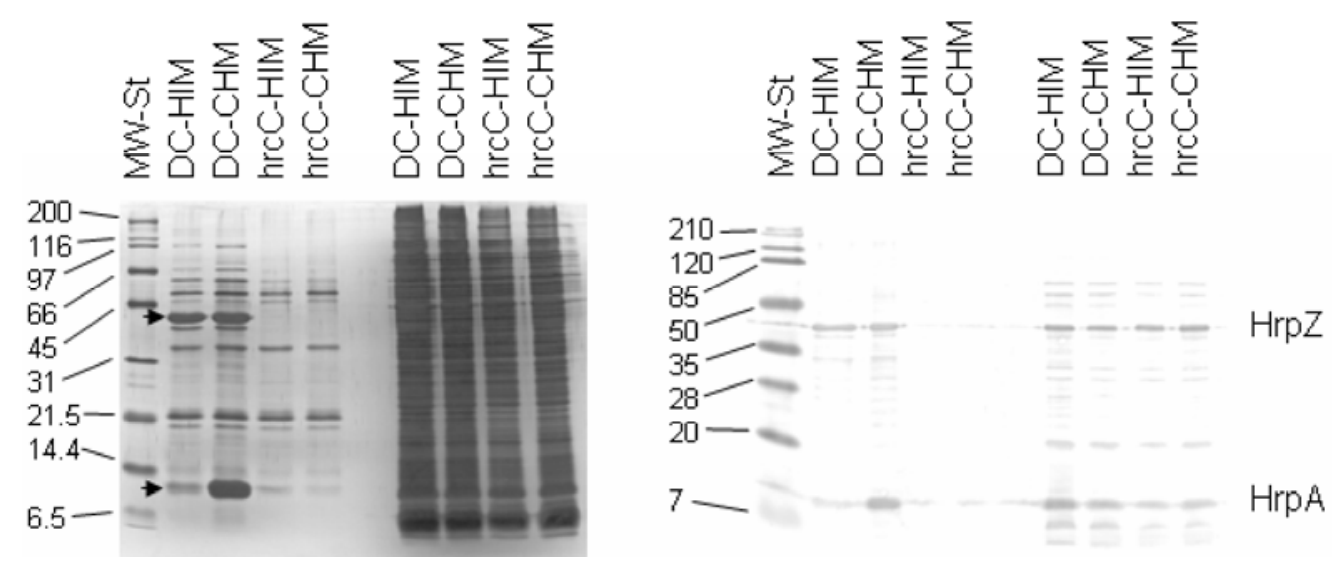

Fig. 6. Protein production and secretion in the hrp-inducing medium (HIM) and HIM supplemented with tomato cell exudates (CHM). Culture supernatant and cell pellet samples of DC3000 and $h r c C$ mutant strain, incubated at $18^{\circ} \mathrm{C}$ for $19 \mathrm{~h}$, were run on two sodium dodecyl sulfate polyacrylamide gels. Left, silverstained gel; right, protein immunoblot probed with HrpA and HrpZ antisera. Loaded lanes: 1, Broad range standards (Biorad); 2 and 3, secreted proteins of DC3000 in HIM and CHM; 4 and 5, secreted proteins of $h r c C$ strain in HIM and CHM; 6-9, samples of cellular proteins of the same cultures. The arrows in the stained gel picture indicate HrpA and HrpZ proteins, and the numbers beside indicate the molecular weights of the standard proteins in kilodaltons. 
moter was similarly induced in the leaves of host plants tomato and A. thaliana and in a nonhost plant, tobacco. Cell cultures derived from Scots pine and deadly nightshade (Atropa belladonna), nonhosts of $P$. syringae pv. tomato, also released compounds enhancing $h r p A$ expression (data not shown). Thus, the outcome of the interaction between a strain of $P$. syringae and a plant, whether compatible or incompatible, is not determined by T3SS induction but by later recognition events.

Phenolic glucosides were previously found to enhance the expression of $s y r B$ and syringomycin production in $P$. syringae pv. syringae (Mo and Gross 1991), whereas Li and associates (1998) found that arbutin and salicin did not enhance the coronatine synthesis in P. syringae pv. tomato DC3000. However, $\mathrm{Li}$ and associates (1998) used an incubation buffer that did not contain fructose, which, according to Mo and Gross (1991), increased $s y r B$ induction several-fold. Because the toxin production and T3SS are both needed for the virulence of $P$. syringae on plants, we tested whether phenolic glucosides added to the minimal medium had an effect on $h r p A$ expression. The results indicated a small enhancement of expression levels, not comparable with the several-fold increase obtained with the tomato cell exudates. It is still possible that the phenolic glucosides were one component of the $h r p$-inducing cocktail released by the tomato cells. The identity of natural hrp-inducers hiding among the hundreds of different secondary metabolites produced by plant cells is still elusive. Whether the inducer is a single compound, a group of similar compounds, or a combination of several different compounds that are recognized by $P$. syringae remains to be solved.

The growth of $P$. syringae pv. tomato was neither enhanced nor suppressed by the tomato cell exudates, which suggests that the inducing effect of the exudates was independent of bacterial multiplication. In King's B medium (KB), hrpA expression was low, even when the bacteria were co-incubated with tomato cells in $\mathrm{KB}$ (data not shown), whereas, in the minimal media, $h r p A$ was always induced in the presence of living tomato cells. This indicates that $\mathrm{KB}$ contains inhibitory substances able to counteract the effect of plant-derived inducers. Thus, hrpA expression level is regulated by both nutritional and plant-specific signals and suppressed by high nutrition levels. Huynh and associates (1989) discovered that the promoter activity of $a v r B$, encoding a T3SS-dependent effector protein of $P$. syringae pv. glycinea, was inversely related to the rate of bacterial growth. Lan and associates (2006) found in their genomic microarray study of $P$. syringae DC3000 that genes associated with basic cellular activities were downregulated by HrpRS, which is a positive regulator of the hrp genes. Our results show that hrp genes are induced by specific signals, not merely by depletion of nutrients, and also that the bacterial cell density affects the hrp expression. In summary, it seems that the induction of $P$. syringae T3SS is dependent on several different factors and, once it has been induced, then the other metabolic pathways are downregulated to ensure effective protein production and secretion via T3SS.

By following a marker gene expression or by reverse-transcription polymerase chain reaction (PCR), it is possible to monitor the transcriptional activity, whereas analysis of the native protein production reveals the final expression levels. When analyzing the protein profiles of $P$. syringae pv. tomato DC3000 in different culture conditions, we found that expression of the Hrp pilus structural unit is under a special posttranscriptional regulation. In addition to the $h r p A$ promoter induction by both environmental and plant-derived signals, the HrpA protein production was further enhanced by plant-derived signals. This effect was not visible with the other T3SS components but was unique to HrpA production. Particularly, it is striking that, although the amounts of HrpA were varying, the harpin HrpZ was always accumulating at the same level in the minimal medium with and without plant exudates. In DC3000, $h r p A$ and $h r p Z$ genes are in the same operon under the $h r p A$ promoter, and there are only $55 \mathrm{bp}$ between the coding regions. The intergene sequence probably forms a loop structure, which stabilizes the hrpA single gene transcript (Hienonen et al. 2004). Although the $\operatorname{hrp} A Z$ co-transcript is not accumulating in the induced cells, the hrpA single-gene mRNA is exceptionally long-living, with a half-life of approximately $40 \mathrm{~min}$ (Hienonen et al. 2004). Thus, it is possible that the high production of HrpA protein in $h r p$-inducing conditions results from the accumulation of the stable mRNA, and specific plant signals could enhance the translation of this mRNA pool. Recently, it was found that the secretion of $\mathrm{HrpA}$ and $\mathrm{HrpZ}$ of P. syringae pv. tomato is also differently controlled: HrpJ was not needed for the secretion of HrpA, whereas it was necessary for the secretion of HrpZ and for the translocation of the effector proteins into the host cells (Fu et al. 2006).

$P$. syringae could control the volume of the type-three protein secretion by the expression level of HrpA pilin and the number of pili formed on the cell surface. The pilus channel is narrow, probably only $2.5 \mathrm{~nm}$ wide; therefore, the secreted proteins must move partially unfolded, one by one in a line. The more numerous secretion machineries and pili were constructed, the more effective the delivery of the effector proteins into the host cells could be. The amount of HrpA protein needed per one T3SS machinery depends on the distance between the bacterium and the plant cell, which is determined by the thickness of the plant cell wall. There may be a mechanism by which $P$. syringae senses when the pilus tip meets the plant cell surface, and our results give indirect evidence supporting this idea. The plant cell exudates were recognized by the bacteria as signals to induce the expression of T3SS-encoding genes. However, when the soluble signals were provided in vitro without the plant cells, only the HrpA protein was produced in considerably higher amounts. This special enhancement of HrpA protein production that we observed could be explained by two regulatory mechanisms: first, the Hrp pilus growth is induced by soluble plant cell signals, and second, contact with the plant cell structures could, in turn, trigger the delivery of the effector proteins.

In conclusion, although the fructose-containing minimal medium is fairly good for the induction of the T3SS of $P$. $s y$ ringae and easy to use, information on how the T3SS is regulated in vivo is missed when using the artificial medium only. On the other hand, studying the bacterial gene expression in plant tissues also has its limitations. In this study, we show that there is a third way: mixing plant cell exudates into the minimal medium can reveal new characteristics of the T3SS regulation by plant-derived signaling compounds.

\section{MATERIALS AND METHODS}

\section{Construction of reporter plasmids.}

A GFP construct (Boureau et al. 2002) carries the hrpA gene and a gene encoding GFP on a low copy number vector, pDN18N. This construct, named pHrpA-GFP113, encodes a full-length HrpA-GFP fusion protein. A luciferase construct carries the $h r p A$ gene and a click beetle luciferase gene, $L U C G R$, on pRK415, a low copy number vector with a broad host range. The hrpA gene of $P$. syringae pv. tomato DC3000, including the $h r p$ box promoter region, was amplified with primers 5'-ATATAGGATCCTGCAAAGACGCTGGAACC-3' (forward) and 5'-ATATAGGATCCTTAGTAACTGATACCTTT AGC-3' (reverse) introducing BamHI sites (underlined) for cloning. The PCR product, comprising the hrpA promoter, the coding region, and the stop codon but not the transcription ter- 
mination loop, was then inserted into pPP (Haapalainen et al. 1996) at the BamHI site $5^{\prime}$ of the LUCGR coding region. Thus, the resulting plasmid construct pHrpALUC was designed to produce a co-transcript of $h r p A$ and $L U C G R$ but not a fusion protein. To construct reporter plasmids pHrpKLUC and pAvrPtoLUC, the native promoters of $h r p K$ and avrPto were amplified by PCR using primers AAA GGT ACC CGT TCG CCT GAA TG and CTC AGG ATC CAG AGC CAG TTC GCC TGG $(h r p K)$ and TGT CGG TAC CCG GCG CCA GC and CTC GAT CCG CCG AC (avrPto). Both of the forward primers introduce a $K p n I$ site in the $5^{\prime}$ end of the promoter fragments. The reverse primer for $h r p K$ promoter introduces a BamHI restriction site to the $3^{\prime}$ end of the fragment. The reverse primer for AvrPto promoter contains a BamHI site originally present in the AvrPto gene. Both promoter fragments harbored the putative hrp box, ribosome-binding site, and translation start site and were $164 \mathrm{bp}(\mathrm{hrpK})$ and $136 \mathrm{bp}$ (AvrPto) in length. These fragments were inserted in pPP $5^{\prime}$ of the $L U C G R$ gene. All the plasmid constructs were first multiplied in Escherichia coli DH5 $\alpha$ (Gibco BRL, Gaithersburg, MD, U.S.A.) before transforming $P$. syringae by triparental mating, with pRK2013 as the helper plasmid. The HrcC mutant of $P$. syringae pv. tomato DC3000 was previously constructed by Yuan and He (1996) and originally called the hrpH mutant. HrcC is a secretin-like multimeric protein which forms the T3SS pore in the bacterial outer membrane, and the $h r c C$ mutant strain is unable to secrete T3SS-dependent proteins (Charkowski et al. 1997).

\section{Culture media for $P$. syringae.}

P. syringae pv. tomato DC3000 and the transformant strains were precultured on KB (King et al. 1954) before starting induction cultures or infiltrating bacteria into plants. The precultured cells were harvested by centrifugation at $4,000 \times g$ at room temperature $\left(22^{\circ} \mathrm{C}\right)$ and resuspended in different Hrp-inducing minimal media to $\mathrm{OD}_{600}=0.3$ to start induction. For preculturing on King's B agar or in King's B broth, the bacteria were incubated at $28^{\circ} \mathrm{C}$, whereas the induction of $h r p$ genes was always performed at $18^{\circ} \mathrm{C}$. The Hrp-inducing medium (HIM) used as a reference was prepared as by Huynh and associates (1989), and it contained $10 \mathrm{mM}$ fructose, $7.6 \mathrm{mM}\left(\mathrm{NH}_{4}\right)_{2} \mathrm{SO}_{4}, 1.7 \mathrm{mM} \mathrm{MgCl} 2$, $1.7 \mathrm{mM} \mathrm{NaCl}$, and $50 \mathrm{mM} \mathrm{KPB}, \mathrm{pH} 5.8$.

\section{Confocal epifluorescence microscopy.}

Bacteria grown in $\mathrm{KB}$ were harvested, resuspended in 10 $\mathrm{mM}$ K-phosphate buffer (KPB), $\mathrm{pH}$ 7.0, and infiltrated in plant leaves at cell densities of $10^{8}$ or $10^{9} \mathrm{CFU} / \mathrm{ml}$, depending on the experimental setup: $10^{9} \mathrm{CFU} / \mathrm{ml}$ was used for short-time observations and measurements and $10^{8} \mathrm{CFU} / \mathrm{ml}$ for overnight incubations. Infiltrations were done with a 1-ml syringe without needle at the underside of the leaves. For microscopy, small pieces of leaf were cut from the infiltrated area and placed into a drop of water on a 1.5-mm cover-glass with Parafilm bordering. The leaf sample was turned a few times in the water drop to ensure wetting, left with the underside up, and covered with a $1.0-\mathrm{mm}$ cover-glass. The two glasses were then sealed together and placed on an aluminum frame so that the thinner glass was on the objective side; thus, the underside of the leaf with the stomata was facing the objective. To get an overview of a leaf full with green pockets of bacteria, a $\times 10$ or $\times 20$ objective was used, whereas the bacterial cells were observed with a $\times 63$ objective with oil. For technical information on the microscope used, see Boureau and associates (2002).

\section{Sample preparation for luciferase assay.}

For in vivo induction of the luciferase expression constructs, tomato (cv. Agriset) and tobacco (cv. Samsun) leaves were infiltrated with bacterial suspension at $\mathrm{OD}_{600}=1.0\left(10^{9} \mathrm{CFU} /\right.$ $\mathrm{ml}$ ) in $10 \mathrm{mM} \mathrm{KPB}, \mathrm{pH}$ 7.2. For sample preparation, the leaves with infiltrated spots were detached and surface sterilized with $15 \% \mathrm{H}_{2} \mathrm{O}_{2}$ in phosphate-buffered saline (PBS) for $10 \mathrm{~min}$ and then rinsed with sterile PBS. Samples of the infiltrated leaf areas were cut out using a $12-\mathrm{mm}$ cork borer. The leaf discs were immersed in $1.5 \mathrm{ml}$ of ice-cold $10 \mathrm{mM} \mathrm{KBP}, \mathrm{pH} \mathrm{7.2,} \mathrm{in}$ plastic tubes, and homogenized with Ultra-Turrax T25 grinder (IKA, Staufen, Germany). To determine the number of viable bacteria, the homogenized leaf samples were diluted in series

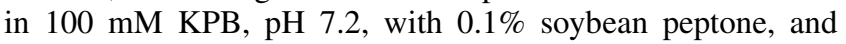
plated on $\mathrm{KB}$ agar supplemented with rifampicin at $75 \mu \mathrm{g} / \mathrm{ml}$. Colonies were counted after 3 days of incubation at $28^{\circ} \mathrm{C}$. Luciferase activity was measured of undiluted leaf homogenates. For in vitro induction, the bacteria were grown in liquid $\mathrm{KB}$ medium to $\mathrm{OD}_{600}=0.2$ to 0.3 , harvested by centrifugation, and resuspended in the induction medium or buffer at $\mathrm{OD}_{600}=$ 0.3 . After incubation at $18^{\circ} \mathrm{C}$ with shaking, luciferase activity was measured.

\section{Luciferase activity assay.}

For preparing $1 \mathrm{ml}$ of luciferin substrate solution, $100 \mu \mathrm{l}$ of 20 $\mathrm{mM}$ luciferin (Sigma-Aldrich, St. Louis); $100 \mu \mathrm{l}$ of $1 \mathrm{M}$ citrate buffer, $\mathrm{pH} 5.0 ; 30 \mu \mathrm{l}$ of $100 \mathrm{mM}$ ATP; and $770 \mu \mathrm{l}$ of water were mixed. The bacterial lysis mix contained one part of solution A (100 mM K-phosphate buffer, pH 7.5, and lysozyme at $5 \mathrm{mg} / \mathrm{ml}$ ) and two parts of solution B (lysis reagent [Promega Corp., Madison, WI, U.S.A.] diluted 1:5 in water and bovine serum albumin, $0.27 \%$ ). For luminescence assay, $100 \mu \mathrm{l}$ of bacterial culture, $100 \mu \mathrm{l}$ of lysis mix, and $100 \mu \mathrm{l}$ of luciferin substrate solution were mixed in a luminometer cuvette, and counts were recorded immediately after insertion of the cuvette into the luminometer, Biocounter M1500 (Lumac, St. Paul, MN, U.S.A.).

\section{Tomato cell culture.}

Solid Murashige-Skoog medium (MS) was prepared with $4.4 \mathrm{~g}$ of MS powder (M0222; Duchefa, Haarlem, The Netherlands), $20 \mathrm{~g}$ of sucrose, and $8 \mathrm{~g}$ of agar per liter. Solid callusinducing medium contained $3.16 \mathrm{~g}$ of Gamborg B5 (GB5) medium (G0210; Duchefa), $30 \mathrm{~g}$ of sucrose, $2 \mathrm{mg}$ of 2,4-D, and 2 $\mathrm{g}$ of gelrite gellan gum (Sigma-Aldrich) per liter, and $0.1 \mathrm{mg}$ of kinetin per liter was added after autoclaving. Suspension culture medium contained GB5 medium and sucrose with 1 $\mathrm{mg}$ of 2,4-D and $0.05 \mathrm{mg}$ of kinetin per liter. The $\mathrm{pH}$ of all the culture media was adjusted to 5.8. Tomato cv. Agriset seed were surface sterilized for $15 \mathrm{~min}$ in $2 \%$ (wt/vol) $\mathrm{NaOCl}$ and $0.05 \%$ (vol/vol) Tween-20, and rinsed several times with sterile water. The surface-sterilized seed were germinated on solid MS medium and grown for 10 days in light at $25^{\circ} \mathrm{C}$. The cotyledons of the tomato seedlings were detached and cut into small pieces, which were placed on the solid callus inducing medium and incubated in darkness at $25^{\circ} \mathrm{C}$. The callus tissues formed were subcultured onto fresh medium every 4 weeks. For preparing suspension cultures, clusters of soft white-yellow callus cells were mixed into $10 \mathrm{ml}$ of suspension culture medium. The suspension cells were cultured in darkness at $25^{\circ} \mathrm{C}$ in Erlenmeyer bottles, with shaking at $100 \mathrm{rpm}$, and diluted into fresh culture medium every week. Both clusters of highly dividing small cells and long expanding cells, dissociated from a cluster, were present in a healthy suspension culture.

\section{Conditioned buffer for induction of $\boldsymbol{P}$. syringae.}

The plant cell culture medium was not suitable for hrpA$L U C$ expression assays; therefore, the cultured plant cells were washed in $10 \mathrm{mM}$ potassium phosphate buffer, $\mathrm{pH} 7.0$. In phosphate buffer, the viability of both the tomato cells and the Pseudomonas cells was well preserved during the 4-h incuba- 
tions. Release of hrp-inducing factors by the tomato cells was highest in a buffer with low ion concentration, the background expression level of $h r p A$ in the bacteria was low, and this buffer also did not interfere with the luciferase activity assay. The tomato suspension cells, in active growing phase, were first washed five times with the $\mathrm{K}$-phosphate buffer supplemented with $1.7 \mathrm{mM} \mathrm{MgCl}_{2}$, and then incubated in it for $4 \mathrm{~h}$ at $25^{\circ} \mathrm{C}$ with $100 \mathrm{rpm}$ shaking. The suspension was then filtered through Miracloth tissue to remove the cells, and this filtrate was sterilized using a $0.2-\mu \mathrm{m}$ low-protein-binding filter. The sterile filtrate, named $\mathrm{CB}$, was either used immediately or stored at $-70^{\circ} \mathrm{C}$. For short inductions of the bacteria, up to $4 \mathrm{~h}$, CB was used as such and, for long inductions of 19 to $20 \mathrm{~h}$, it was mixed with the $h r p$-inducing medium ingredients to $93 \%$ of the total volume, to prepare CHM. Because $1.7 \mathrm{mM} \mathrm{MgCl} 2$ was already included in $\mathrm{CB}$, it was not added at this step.

\section{Characterization of the $h r p$-inducing factor.}

Components of the tomato cell conditioned buffer were fractionated by size using Microcon and Ultrafree centrifugal filter units (Millipore, Billerica MA, U.S.A.) with molecular size cutoff from 5 to $100 \mathrm{kDa}$, according to the manufacturer's instructions. The materials retained on the filters were resuspended in $10 \mathrm{mM} \mathrm{K}$-phosphate buffer to the original sample volume. Heat stability of the active factor was tested by heating aliquots of the conditioned buffer at $100^{\circ} \mathrm{C}$ for $10 \mathrm{~min}$. For testing sensitivity to a protease, aliquots were incubated with proteinase $\mathrm{K}$ at $50 \mu \mathrm{g} / \mathrm{ml}$ of sample, at $37^{\circ} \mathrm{C}$ for $30 \mathrm{~min}$. The enzyme was then inactivated at $75^{\circ} \mathrm{C}$ for $10 \mathrm{~min}$. Control samples were incubated at the same temperatures without the enzyme. Hydrophobic and ionic interactions of the inducing factor were characterized by fractionating the conditioned buffer with different Chromafix solid-phase chromatography cartridges (MachereyNagel, Düren, Germany). HR-P resin consists of polystyrene and divinylbenzene, whereas $\mathrm{OH}$ resin consists of diol silica. $\mathrm{C} 18$, C18ec, C18hydra, and C8 are silica-based resins with octadecyl and octyl ligands that bind nonpolar compounds. All the different fractions and differentially treated aliquots of the tomato cell exudates were tested on the pHrpALUC transformant strain for induction of $h r p A$ promoter by incubation of the bacteria in each fraction at $18^{\circ} \mathrm{C}$ for $4 \mathrm{~h}$ with shaking. Luminescence was then measured as described above.

\section{Analysis of proteins secreted under $\boldsymbol{h r p}$-inducing conditions.}

P. syringae pv. tomato $\mathrm{DC} 3000$ and $h r c C$ mutant strains were first cultured in $\mathrm{KB}$ medium from $\mathrm{OD}_{600}=0.1$ to 0.3 (3.5 $\mathrm{h}$ at $28^{\circ} \mathrm{C}$ ) and then in the $h r p$-inducing media, HIM and $\mathrm{CHM}$, starting from $\mathrm{OD}_{600}=0.3$. After $19 \mathrm{~h}$ of incubation at $18^{\circ} \mathrm{C}$, the cultures were centrifuged at $8,000 \times g$ for $15 \mathrm{~min}$ at $4^{\circ} \mathrm{C}$. The supernatants were then filtered through $0.45-\mu \mathrm{m}$ Filtropur S filters (Sarstedt, Nümbrecht, Germany) to remove all the bacterial cells, and protease inhibitor phenyl methyl sulfonyl fluoride was added to $0.5 \mathrm{mM}$ concentration. A sample of $1 \mathrm{ml}$ in volume was taken from each culture supernatant filtrate and the proteins were precipitated by trichloroacetic acid. The precipitated proteins were washed once with cold acetone and, after evaporation of the acetone, resuspended in standard sodium dodecyl sulfate polyacrylamide gel electrophoresis loading buffer, heated, and run on two $14 \%$ polyacrylamide gels. Proteins on one gel were silver stained and those on the other gel were blotted onto polyvinylidene difluoride membrane for immunodetection. HrpA and HrpZ were detected with specific antisera and secondary monoclonal anti-rabbit immunoglobulin $\mathrm{G}$ antibodies, conjugated with alkaline phosphatase (SigmaAldrich). The phosphatase activity was then detected by color reaction with NBT and BCIP reagents (Promega Corp.).

\section{ACKNOWLEDGMENTS}

We thank S. Kaur and H. Hulkko for technical assistance. The Academy of Finland is acknowledged for financing the project and the Centre for International Mobility for awarding a scholarship to K. Van Gestel.

\section{LITERATURE CITED}

Aldon, D., Brito, B., Boucher, C., and Genin, S. 2000. A bacterial sensor of plant cell contact controls the transcriptional induction of Ralstonia solanacearum pathogenicity genes. EMBO (Eur. Mol. Biol. Organ.) J. 19:2304-2314.

Boureau, T., Routtu, J., Roine, E., Taira, S., and Romantschuk, M. 2002. Localization of hrpA-induced Pseudomonas syringae pv. tomato DC3000 in infected tomato leaves. Mol. Plant Pathol. 3:451-460.

Brown, I. R., Mansfield, J. W., Taira, S., Roine, E., and Romantschuk, M. 2001. Immunocytochemical localization of HrpA and HrpZ supports a role for the Hrp pilus in the transfer of effector proteins from Pseudomonas syringae pv. tomato across the host plant cell wall. Mol. PlantMicrobe Interact. 14:394-404.

Charkowski, A. O., Huang, H.-C., and Collmer, A. 1997. Altered localization of HrpZ in Pseudomonas syringae pv. syringae hrp mutants suggests that different components of the type III secretion pathway control protein translocation across the inner and outer membranes of gramnegative bacteria. J. Bacteriol. 179:3866-3874.

Cornelis, G. R. 2006. The type III secretion injectisome. Nat. Rev. Microbiol. 4:811-825.

Deane, J. E., Roversi, P., Cordes, F. S., Johnson, S., Kenjale, R., Daniell, S., Booy, F., Picking, W. D., Picking, W. L., Blocker, A. J., and Lea, S. M. 2006. Molecular model of a type III secretion system needle: Implications for host-cell sensing. Proc. Natl. Acad. Sci. U.S.A. 103:1252912533.

Fu, Z. Q., Guo, M., and Alfano, J. R. 2006. Pseudomonas syringae HrpJ is a type III secreted protein that is required for plant pathogenesis, injection of effectors, and secretion of the HrpZ1 harpin. J. Bacteriol. 188:6060-6069.

Grant, S. R., Fisher, E. J., Chang, J. H., Mole, B. M., and Dangl, J. L. 2006. Subterfuge and manipulation: Type III effector proteins of phytopathogenic bacteria. Annu. Rev. Microbiol. 60:425-449.

Haapalainen, M., Karp, M., and Metzler, M. C. 1996. Isolation of strong promoters from Clavibacter xyli subsp. cynodontis using a promoter probe plasmid. Biochim. Biophys. Acta 1305:130-134.

Hauck, P., Thilmony, R., and He, S.-Y. 2003. A Pseudomonas syringae type III effector suppresses cell wall-based extracellular defense in susceptible Arabidopsis plants. Proc. Natl. Acad. Sci. U.S.A. 100:85778582

Hienonen, E., Rantakari, A., Romantschuk, M., and Taira, S. 2004. The bacterial type III secretion system-associated pilin HrpA has an unusually long mRNA half-life. FEBS (Fed. Eur. Biochem. Soc.) Lett. 571:217-220

Hueck, C. J. 1998. Type III protein secretion systems in bacterial pathogens of animals and plants. Microbiol. Mol. Biol. Rev. 62:379-433.

Hutcheson, S. W., Bretz, J., Sussan, T., Jin, S., and Pak, K. 2001. Enhancer-binding proteins HrpR and HrpS interact to regulate hrp-encoded type III protein secretion in Pseudomonas syringae strains. J. Bacteriol. 183:5589-5598.

Huynh, T. V., Dahlbeck, D., and Staskawicz, B. J. 1989. Bacterial blight of soybean: Regulation of a pathogen gene determining host cultivar specificity. Science 245:1374-1377.

King, E. O., Ward, M. K., and Raney, D. E. 1954. Two simple media for the demonstration of pyocyanin and fluorescein. J. Lab. Clin. Med. 22:301-307.

Lan, L., Deng, X., Zhou, J., and Tang, X. 2006. Genome-wide gene expression analysis of Pseudomonas syringae pv. tomato DC3000 reveals overlapping and distinct pathways regulated by hrpL and hrpRS. Mol. Plant-Microbe Interact. 19:976-987.

Li, C.-M., Brown, I., Mansfield, J., Stevens, C., Boureau, T., Romantschuk, M., and Taira, S. 2002. The Hrp pilus of Pseudomonas syringae elongates from its tip and acts as a conduit for translocation of the effector protein HrpZ. EMBO (Eur. Mol. Biol. Organ.) J. 21:1909-1915.

Li, X.-Z., Starrat, A. N., and Cuppels, D. A. 1998. Identification of tomato leaf factors that activate toxin gene expression in Pseudomonas syringae pv. tomato DC3000. Phytopathology 88:1094-1100.

Marie, C., Broughton, W. J., and Deakin, W. J. 2001. Rhizobium type III secretion systems: Legume charmers or alarmers? Curr. Opin. Plant Biol. 4:336-342.

Mo, Y.-Y., and Gross, D. C. 1991. Plant signal molecules activate the syrB gene, which is required for syringomycin production by Pseudomonas syringae pv. syringae. J. Bacteriol. 173:5784-5792. 
Petnicki-Ocwieja, T., Van Dijk, K., and Alfano, J. R. 2005. The hrpK operon of Pseudomonas syringae pv. tomato DC3000 encodes two proteins secreted by the type III (Hrp) protein secretion system: HopB1 and HrpK, a putative type III translocator. J. Bacteriol. 187:649-663.

Rahme, L. G., Mindrinos, M. N., and Panopoulos, N. J. 1992. Plant and environmental sensory signals control the expression of hrp genes in Pseudomonas syringae pv. phaseolicola. J. Bacteriol. 174:3499-3507.

Roine, E., Wei, W., Yuan, J., Nurmiaho-Lassila, E.-L., Kalkkinen, N., Romantschuk, M., and He, S. Y. 1997. Hrp pilus: An hrp-dependent bacterial surface appendage produced by Pseudomonas syringae pv. tomato DC3000. Proc. Natl. Acad. Sci. U.S.A. 94:3459-3464.

Rosqvist, R., Magnusson, K.-E., and Wolf-Watz, H. 1994. Target cell contact triggers expression and polarized transfer of Yersinia YopE cytotoxin into mammalian cells. EMBO (Eur. Mol. Biol. Organ.) J. 13:964972.

Thwaites, R., Spanu, P. D., Panopoulos, N. J., Stevens, C., and Mansfield, J. W. 2004. Transcriptional regulation of components of the type III se- cretion system and effectors in Pseudomonas syringae pv. phaseolicola. Mol. Plant-Microbe Interact. 17:1250-1258.

Toruellas, J., Jackson, M. W., Pennock, J. W., and Plano, G. V. 2005. The Yersinia pestis type III secretion needle plays a role in the regulation of Yop secretion. Mol. Microbiol. 57:1719-1733

Van Dijk, K., Fouts, D. E., Rehm, A. H., Hill, A. R., Collmer, A., and Alfano, J. R. 1999. The Avr (effector) proteins HrmA (HopPsyA) and AvrPto are secreted in culture from Pseudomonas syringae pathovars via the Hrp (type III) protein secretion system in a temperature- and pH-sensitive manner. J. Bacteriol. 181:4790-4797.

Xiao, Y., and Hutcheson, S. W. 1994. A single promoter sequence recognized by a newly identified alternate sigma factor directs expression of pathogenicity and host range determinants in Pseudomonas syringae. J. Bacteriol. 176:3089-3091.

Yuan, J., and He, S.-Y. 1996. The Pseudomonas syringae Hrp regulation and secretion system controls the production and secretion of multiple extracellular proteins. J. Bacteriol. 178:6399-6402. 